\title{
Product Development, Biochemical and Organoleptic Analysis of a Sports Drink.
}

\author{
Ms. Vaibhavi V. Gujar, Ms. Bhakti V. Gala \\ Department of Biochemistry \& Food Science and Quality Control, Ramnarain Ruia College, Matunga, \\ Mumbai - 400019, Maharashtra, INDIA
}

\begin{abstract}
There is a large amount of evidence showing that an individual undergoing dehydration (during a tournament or the exercise regimen) has a negative impact on performance. Thus restoration of this fluid balance must be achieved. Sports drinks are ideally placed to fill both these roles. A sports drink is a beverage designed to help athletes rehydrate, as well as replenish electrolytes, sugars and other nutrients that are lost or depleted after strenuous exercise, training or competition. However, in a sports drink, a variety of substances and nutrients are dissolved in water to make the final product. Not only that, a variety of fruit juices can also be added which provide natural flavor and color rather than adding the artificial ones. In this project, a sports drink was developed mainly using Anandi variety of pomegranate (Punica granatum) and kokum (Garcinia indica). These fruits not only provide natural flavor and color, but also minerals which are essential for the enhancement of athletes' performance. These fruits are available throughout the year and hence, were selected. Proximate, biochemical, microbiological and sensory properties of the developed product were analyzed. The sports drink product was isotonic. It contained $6.33 \%$ of carbohydrate, and $105.6 \mathrm{mg} / 100 \mathrm{ml}$ of vitamin C which allows the sports drink for easy gastric emptying and intestinal absorption. The electrolytes present in the sports drink were similar to those lost through sweating and were obtained as; potassium (33.99 $\mathrm{mg} \%$ ), sodium (65.75 $\mathrm{mg} \%)$, phosphate (4.085mg \%), chloride (394.4 $\mathrm{mg} \%$ ), calcium (8 $\mathrm{mg} \%)$, magnesium (4.86 $\mathrm{mg} \%$ ) and iron $(0.72 \mathrm{mg} \%)$. Results from the Minimum Inhibitory Concentration and Real Time Polymerase Chain Reaction (RT-PCR) confirmed the bactericidal property of the sports drink. The presence of antioxidants, led to the enhancement of the formulation, making it a better sports drink. Also, the study examined the extent to which the sports drink caused dental erosion as compared to that of the branded sports drink. The effect of the sports drink in comparison to that of water, on the performance of young sprinters was also analyzed and the sports drink provided positive results. Sensory evaluation gave an idea regarding the overall acceptability of the developed sports drink.
\end{abstract}

Keywords: Biochemical, microbiological, organoleptic, sports drink, minimum inhibitory concentration, dental erosion.

\section{Introduction:}

A sport drink is a beverage designed to help athletes rehydrate, as well as replenish electrolytes, sugars and other nutrients that are lost or depleted after strenuous exercise, training or competition (Berning et al., 1998). Companies marketing these products point out the fact that plain water, despite its association with good health, can be toxic if consumed in large amount (water intoxication). This can happen because over consumption of water reduces levels of electrolytes such as sodium and potassium in the body by dilution, interfering with the nervous system. Sports drinks are popular among athletes because they provide the necessary electrolytes to support extended exercise. They help keep the body balanced and contain the right amount of electrolyte in the fluids. However, not all drinks advertised as sports drinks are suitable for this purpose, and professional advice should be sought for potentially risky situations.

Keeping in mind the nutritional significance and it's property to relish the energy stores, the sports drink developed is composed of the following major constituents: Pomegranate (Punica granatum), Kokum (Garcinia indica), Cumin. These constituents not only add on to the flavor of the drink but also provide nourishment in the form of electrolytes and help in fluid replacement.

a) Pomegranate: The pomegranate, botanical name Punica granatum, is a fruit bearing deciduous shrub.

\section{Health Benefits of Pomegranate Juice}

The juice of pomegranate contains antioxidants like anthocyanin and ellagic acid, compounds like gallic acids, and flavonoids like quercetin which offer protection from diabetes, heart diseases, osteoarthritis and several kinds of cancer. Although pomegranate juice contains fructose, it does not elevate the blood sugar level as other fruit juices do. Pomegranates are also known to reduce high blood pressure. Pomegranate juice eliminates free radicals from the body and inhibits the growth and development of cancer and other diseases. 
Pomegranate juice is used in the treatment of diarrhea and dysentery as it plays a vital role in the secretion of enzymes which aids proper digestion.

b) KOKUM: Garcinia indica, a plant in the mangosteen family (Clusiaceae), commonly known as kokum, is a fruit-bearing tree that has culinary, pharmaceutical, and industrial uses.

Health Benefits of Kokum Syrup

Kokum juice is very popular in India especially during hot summer. It is delicious and has a cooling effect on the body. It not only quenches your thirst, but also helps to prevents dehydration and sunstroke due to heat. Kokum juice improves the digestion and appetite. It is also used to treat piles and dysentery. It promotes cell regeneration and repair. It helps to reduce fever and allergic reactions.

c) CUMIN: Cumin (Cuminum cyminum) is a flowering plant in the family Apiaceae.

\section{Health Benefits of Cumin Seeds}

Cumin seeds contain numerous phyto-chemicals that are known to have antioxidant, carminative and anti-flatulent properties. The active principles in the cumin may augment the motility of the gastro-intestinal tract as well as aids in the digestion power by increasing gut enzyme secretions. This spice is an excellent source of minerals like iron, copper, calcium, potassium, manganese, selenium, zinc and magnesium.

\section{Materials and Methods:}

A Sports drink was developed using pomegranate, kokum and cumin and was pasteurized at $70^{\circ} \mathrm{C}$ for half an hour. It was then stored in glass bottles at a temperature of about $5^{\circ} \mathrm{C}$. The analysis of sports drink for proximate principles like water content, carbohydrates, proteins, crude fibers were performed. Also analysis of minerals like chloride, calcium, iron, phosphorus, magnesium, potassium, sodium, vitamin c was performed using standard biochemical methods. Titrable acidity, osmolality, antioxidant activity, MIC, Real Time Polymerase chain Reaction were performed in order to study the sports drink's antioxidant and antibacterial activity. The effects of sports drink on dental erosion and further on the sprinters were studied. Sensory evaluations of the developed sports drink as Sample A and the branded sports drink as Sample B was carried out by semi trained panelists and athletes, to analyze the acceptance of the formulated sports drink.

\section{Results and Discussions:}

Sports drink is a beverage designed to help athletes rehydrate, as well as replenish electrolytes, sugars and other nutrients that are lost or depleted after strenuous exercise, training or competition. Keeping in mind the importance of electrolytes, the necessity of energy recovery and the antibacterial property, all leading to an enhancement in the performance of the athletes, a sports drink was developed. The developed sports drink was isotonic.

From the proximate analysis:

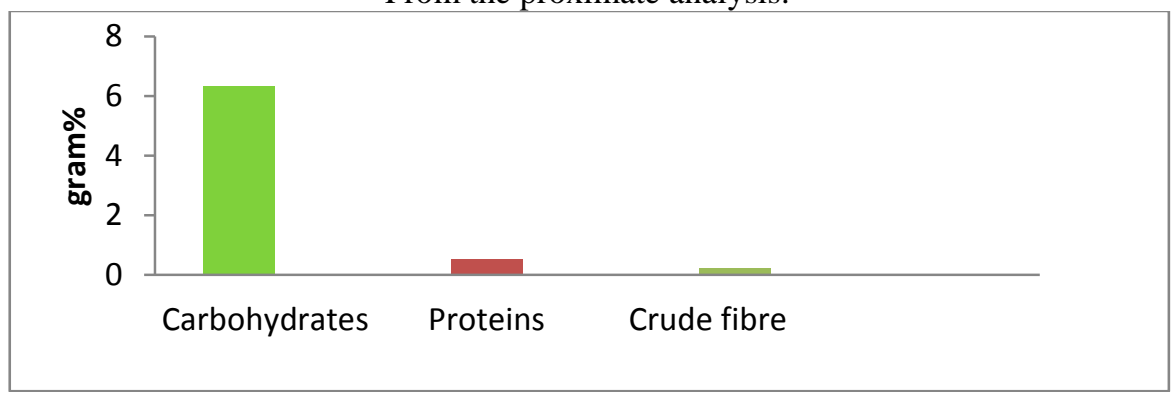

The content of minerals and nutrients were studied. Sports drink with the carbohydrate content between 6-8\% helps to maximize gastric emptying, enhance fluid absorption from the intestine, as well as supply energy to the working muscle. The developed drink contains a very small amount of proteins. Some studies show that sports drinks providing protein/amino acids are superior to carbohydrate-electrolyte drinks in enhancing performance or recovery in specific exercise situations. 
Electrolyte level in sports drink:
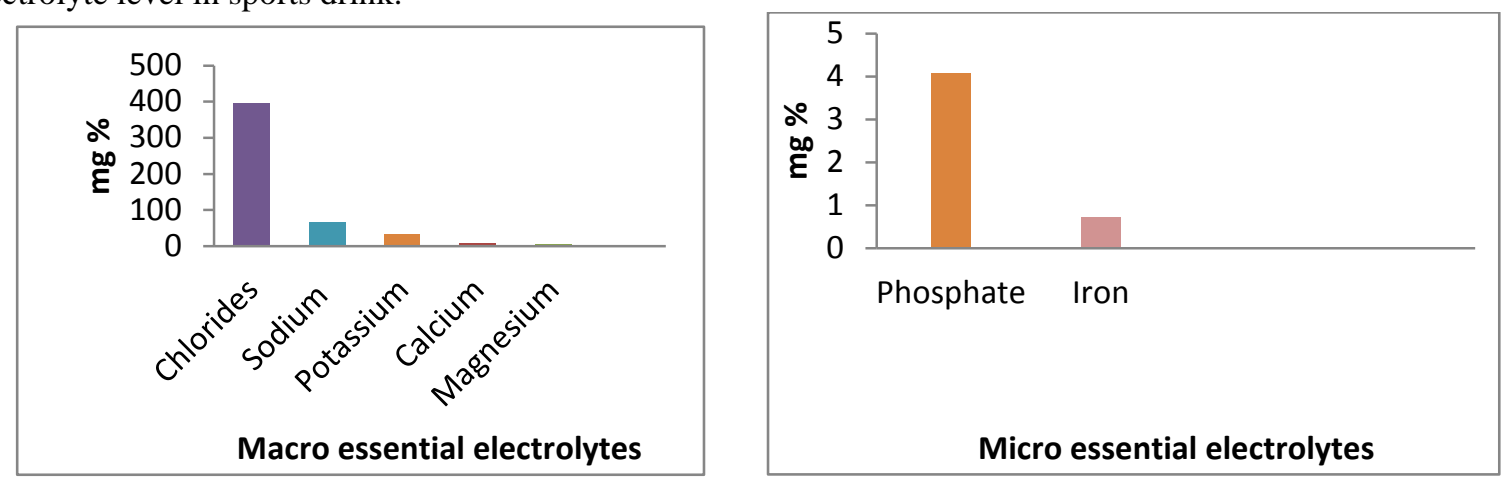

The developed sports drink contains $0.234 \%$ of ash. Ash gives an indication of the amount of minerals in a sample. Sports drinks are used to replace electrolytes that are lost through sweat. Electrolytes lost through the sweat mainly comprise of sodium, potassium, calcium and chloride. The sodium in the sports drink contributes to palatability and also encourages drinking as well replacing that lost through sweat. Potassium affects heartbeat and aids muscle contraction. Calcium combines with other minerals within a protein framework to give structure and strength to bones and teeth, also calcium assists in blood clotting so whenever there is an open cut it helps prevent loss of blood (Haris, 1996). This nutritional composition makes the sports drink an excellent choice for sports men. Vitamin $\mathrm{C}$ is not usually found in the branded sports drink. Pomegranate as well as Kokum, have both individually contributed to higher levels of vitamin $\mathrm{C}$ in the developed sports drink.

From dental erosion studies:

\begin{tabular}{|c|c|c|c|c|c|c|}
\hline & \multicolumn{3}{|c|}{ After 1 hour } & \multicolumn{3}{|c|}{ After 3 hours } \\
\hline Beaker containing & $\begin{array}{c}\mathrm{A} \\
\text { (in } \mathbf{c m})\end{array}$ & $\begin{array}{c}B \\
\text { (in } \mathbf{c m})\end{array}$ & $\begin{array}{l}\text { Difference } \\
(\text { A-B }) \mathrm{cm}\end{array}$ & $\begin{array}{c}\mathrm{A} \\
\text { (in } \mathbf{~ c m})\end{array}$ & $\begin{array}{c}\text { B } \\
\text { (in cm) }\end{array}$ & $\begin{array}{l}\text { Difference } \\
(A-B) \mathrm{cm}\end{array}$ \\
\hline Water (control) & 2.4 & 1.9 & 0.5 & 4.5 & 4.1 & 0.4 \\
\hline $\begin{array}{l}\text { Developed sports drink } \\
\text { (Sample 1) }\end{array}$ & 2.7 & 2.35 & 0.35 & 5.0 & 4.75 & 0.25 \\
\hline $\begin{array}{l}\text { Branded sports drink } \\
\text { (Sample 2 ) }\end{array}$ & 2.6 & 2.5 & 0.1 & 5.0 & 4.95 & 0.05 \\
\hline
\end{tabular}

The total acid level (titratable acid) of acidic drinks is considered to be more important than pH alone as this determines the concentration of damaging hydrogen ions available to interact with the tooth surface. The developed sports drink being on the acidic side, caused dental erosion but to a lesser extent than that of the branded one. This may be because the branded sports drink had a lower $\mathrm{pH}$ and a very high titrable acidity than that of the developed sports drink. It has been found that drinks with higher $\mathrm{pH}$, lower titratable acidity, and higher concentrations of calcium and phosphate reduce the erosive potential. As the branded sports drink lacked calcium and phosphate ions, it might have resulted to a higher erosive potential. Hence, sugar-free gum after drinking increases the amount of saliva in the mouth. This helps to correct the mouth's acidity levels. Rinsing with water has similar effects. Hence, it can help to reduce dental erosion caused due to consumption of sports drink.

From antioxidant activity:

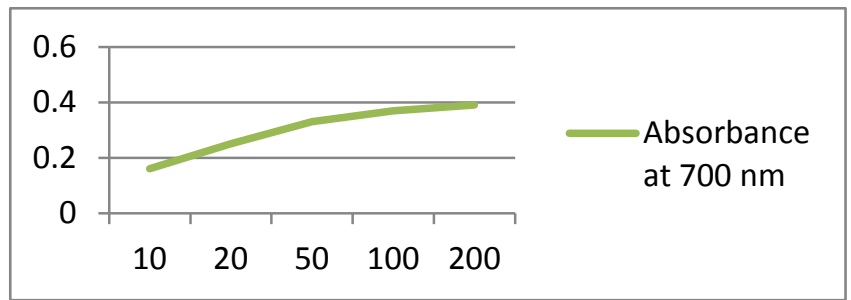

This activity was observed mainly due to the phenolic compounds present in the respective juices. As the concentration of pomegranate juice used was higher than that of kokum, the major antioxidant activity would be due to the pomegranate. The main phenolic compounds present in pomegranate juice can be arranged into four groups. This includes the anthocyanin pigments, the hydrolyzable tannins of the gallagyl type, which are the punicalagin isomers; also punicalins, ellagic acid and its glycosides. 
From antibacterial studies:

a) Sample treated with sports drink

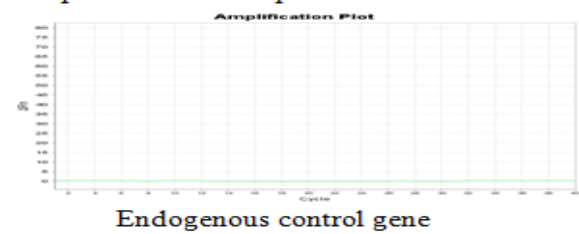

b) Untreated sample
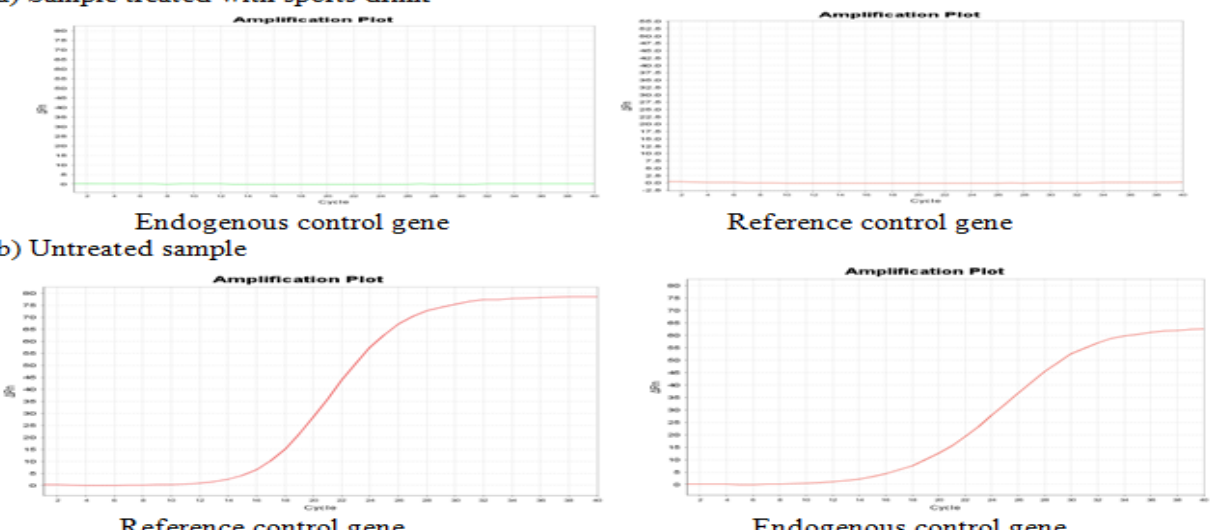

Endogenous control gene

c) No template control

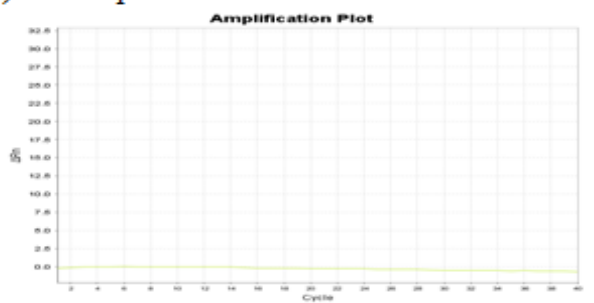

Reference control gene

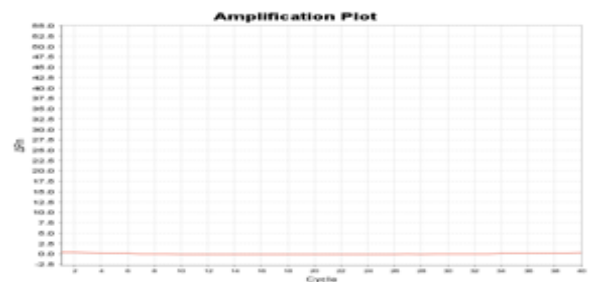

Endogenous control gene

Sports drink prepared was investigated for its effect on the Escherichia coli, which is the normal flora of human gastro-intestinal tract. The minimal inhibitory concentration of the aqueous extract, as a measure of susceptibility of the microbe to the extract, was determined using the broth tube dilution method. The results obtained using the above mentioned microbiological technique was evaluated using a highly sensitive Real time polymerase chain reaction (RT-PCR).

The Minimal Inhibitory Concentration of the sports drink formulation was found to be $60 \%$. The DNA extracted from the dilution tubes exhibiting MIC was qualitatively analyzed on agarose gel. The bacterial 16S rRNA gene and fimbria gene were used as reference gene and endogenous control respectively. The ct (cycle threshold) value of the reference gene and endogenous gene for both, the untreated sample and the sample treated with the sports drink prepared were compared. In case of treated sample the ct values for both reference gene and endogenous gene were undetermined. As ct value is inversely proportional to the amount of starting DNA template, an absence of DNA was confirmed for the sample treated with sports drink. This anti microbial activity would be mainly due to the phytocompounds including phenols, tannins and flavanoids in the pomegranate as well as the kokum extract and cumin.

The developed sports drink was further tested on the sprinters to check whether it enhanced the sprinters' performance. The time taken by sprinters to complete the race after consumption of water, and that of the sports drink was noted. It was hence observed that they required comparatively less time to finish the race after consuming the sports drink than that taken after consuming water. Sports drinks provide carbohydrate energy to working muscles, stimulate rapid rehydration and can actually encourage you to drink enough fluid to avoid dehydration all without any adverse side effects. Therefore, sports drinks can have a positive effect on performance and are recommended for events or exercise sessions lasting longer than one hour.

From Sensory evaluation:

Semi trained panelist

Athletes
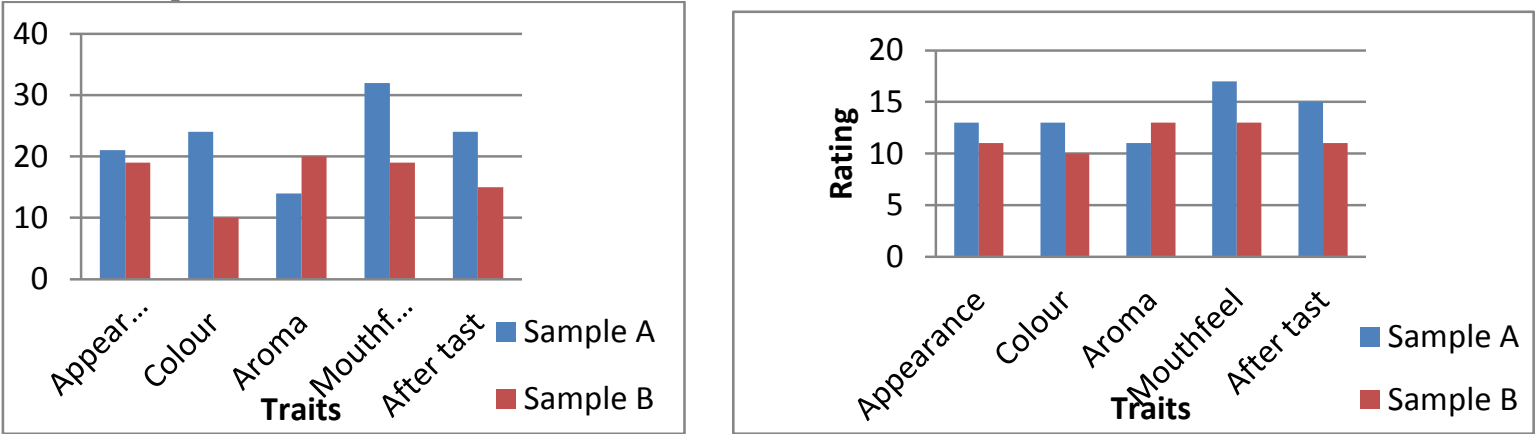
From sensory evaluation studies, the calculated values are lower than the chi square table value at 5\% significance. Thus, the assumption that the "the two events are independent of each other and hence not associated" is accepted. The overall rating and acceptability for the developed sports drink was more. The aroma of the branded sports drink was preferred. This may be due to the synthetic flavor added which made the drink more appealing. Thus, the study based on sensory evaluation displayed that the developed sports drink was preferred over the branded one by the semi trained panel, as well as the athletes.

\section{Conclusion:}

From the results obtained a sports drink can be prepared from pomegranate juice and kokum concoction in a ratio of 50 percent of pomegranate juice to 50 percent of kokum water. This can be pasteurized at a temperature of $70^{\circ} \mathrm{C}$ and preserved. The developed sports drink has vitamin $\mathrm{C}$ content of $105.6 \mathrm{mg} / 100 \mathrm{ml}$, and percentage carbohydrate of $6.33 \%$ making it easy for gastric emptying. Also, the electrolytes present in the developed sports drink, help replace the ones lost through sweat and thus, help replenish the energy stores. It helps reduce dental erosion and helps maintain good oral health. The sports drink also contains high amounts of polyphenolic compounds like gallic acid, punicalagins and other hydrolysable tannins, which have an anti inflammatory activity and help reduce muscle swellings in case of physical injury. Also, the sports drink possesses an antibacterial activity, making it an effective drink. The sensory evaluation provides an idea regarding the acceptability of the developed sports drink. The use of natural juices not only provides carbohydrates, but also other electrolytes and polyphenolic compounds which may help improve performance. These parameters make the formulation a good sports drink and with the availability of the raw materials throughout the year this product could be economically viable.

\section{Acknowledgements:}

I would like to express deep gratitude and appreciation to Dr. (Mrs.) Jyoti. D. Vora (Guide Head, Department of Biochemistry \& Food Science and Quality Control Ramnarain Ruia College, Matunga) for her valuable guidance, continued advice, helpful criticisms and patience at every stage of this study.

\section{References:}

[1]. Applied sciences: Medicine and science in sports and exercise. Hopkins WG, Hawley JA, Burke LM. Vol. 31, No. 3, pp. 472-485, 1999.

[2]. Faculty of sport sciences, Waseda University. Suzuki K, Hashimoto H, Oh T, Ishijima T, Mitsuda H, M Peake J, Sakamoto S, Muraoka I, Higuchi M. Vol. 59, No. 3, pp. 206-212, 2013

[3]. Journal of Sports Medicine. Jeukendrup, Asker E, Jentjens Roy.Vol. 29, No. 6, pp. 407-424, 2000

[4]. Journal of sports science, M. S. El Sayed; J. Balmer; A. J. M. Rattu. Vol. 15, Issue 2, March 1997.

[5]. Journal of sports nutrition. Glenn K. McConell, Benedict J. Canny, Marcus C. Daddo, Marcus J. Nance, Rodney J. Snow. Department of Physiology, Monash University, Clayton, Victoria 3168 and School of Health Sciences, Deakin University, Burwood, Victoria, 3125, Australia.

[6]. Applied physiology. Jentjens RL, Venables MC, Jeukendrup AE.Vol. 96, No. 4, pp. 1285-91, December 2003

[7]. J International Society Of Sports Nutrition. Tomlin DL, Clarke SK, Day M, McKay HA, Naylor PJ.Vol. 10, No. 3, pp. 1550-2738, August 2013European Journal of Nutrition.

[8]. Pakistan Journal of Pharmaceutical Science Awan UA, Andleeb S, Kiyani A, Zafar A, Shafique I, Riaz N, Azhar MT, Uddin H.Vol. 26, No. 6, pp. 1109-16, November 2013

[9]. Journal of Academic Nutrition Diet. Park S, Onufrak S, Blanck HM, Sherry B.Vol.113, No. 1, pp. 112-9, January 2013.

[10]. AOAC, 1999. Official Methods of Analysis. 16th Edition, 5th Reversion, AOAC International, Gaithersburg, MD.

[11]. Position Stand: exercise and fluid replacement. Medicine and Science in Sports and Exercise. 28, i-vii.

[12]. Sweating: its composition and effect on body fluids. Annals of New York Academy of Science. Costill, D. L., 1977. 301:160-174

[13]. Human intestinal water absorption: direct versus indirect measurements. American Journal of Physiology, Gilsolfi, C.V., Summers, R.W., Schedl, H.P., Bleider, T.L. and Oppliger, R.A., 1990. 258, 216-222.

[14]. The volume and energy content of meals as determinants of gastric emptying. Journal of Physiology, Hunt, J.N., and Stubbs D.F., 1975. 254, 209-225.

[15]. Oral hydration solutions: experimental optimization of water and sodium absorption. Journal Pediatrics, Lifshitz, F., and Wapnir, R. A., 1985. 106 (3):383-9.

[16]. The influence of volume on gastric emptying and fluid balance during prolonged exercise. Medicine and Science in Sports and Exercise. Mitchell, J. B. and Voss, K.W., 1990. 23, 314-319.

[17]. Influence of body water and blood volume on thermoregulation and exercise performance in the heat. Exercise and Sports Science Reviews, Sawka, M.N, and Coyle, E, F., 2005. 27:167-218. 